$12-1996$

\title{
Using Information Technology Strategically in Home Care
}

Jerry A. Benson

Jeffrey E. Michelman

University of North Florida, jeff.michelman@unf.edu

Doreen Radjenovic

Follow this and additional works at: https://digitalcommons.unf.edu/bacc_facpub

Part of the Computer Sciences Commons, and the Nursing Commons

\section{Recommended Citation}

Benson, Jerry A.; Michelman, Jeffrey E.; and Radjenovic, Doreen, "Using Information Technology Strategically in Home Care" (1996). Accounting and Finance Faculty Publications. 4.

https://digitalcommons.unf.edu/bacc_facpub/4

This Article is brought to you for free and open access by the Department of Accounting and Finance at UNF Digital Commons. It has been accepted for inclusion in Accounting and Finance Faculty Publications by an authorized administrator of UNF Digital Commons. For more information, please contact Digital Projects.

(C) 12-1996 All Rights Reserved

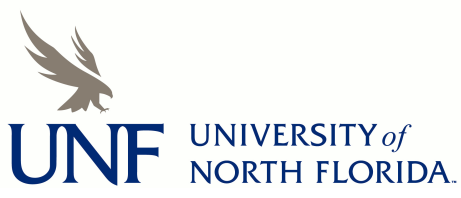




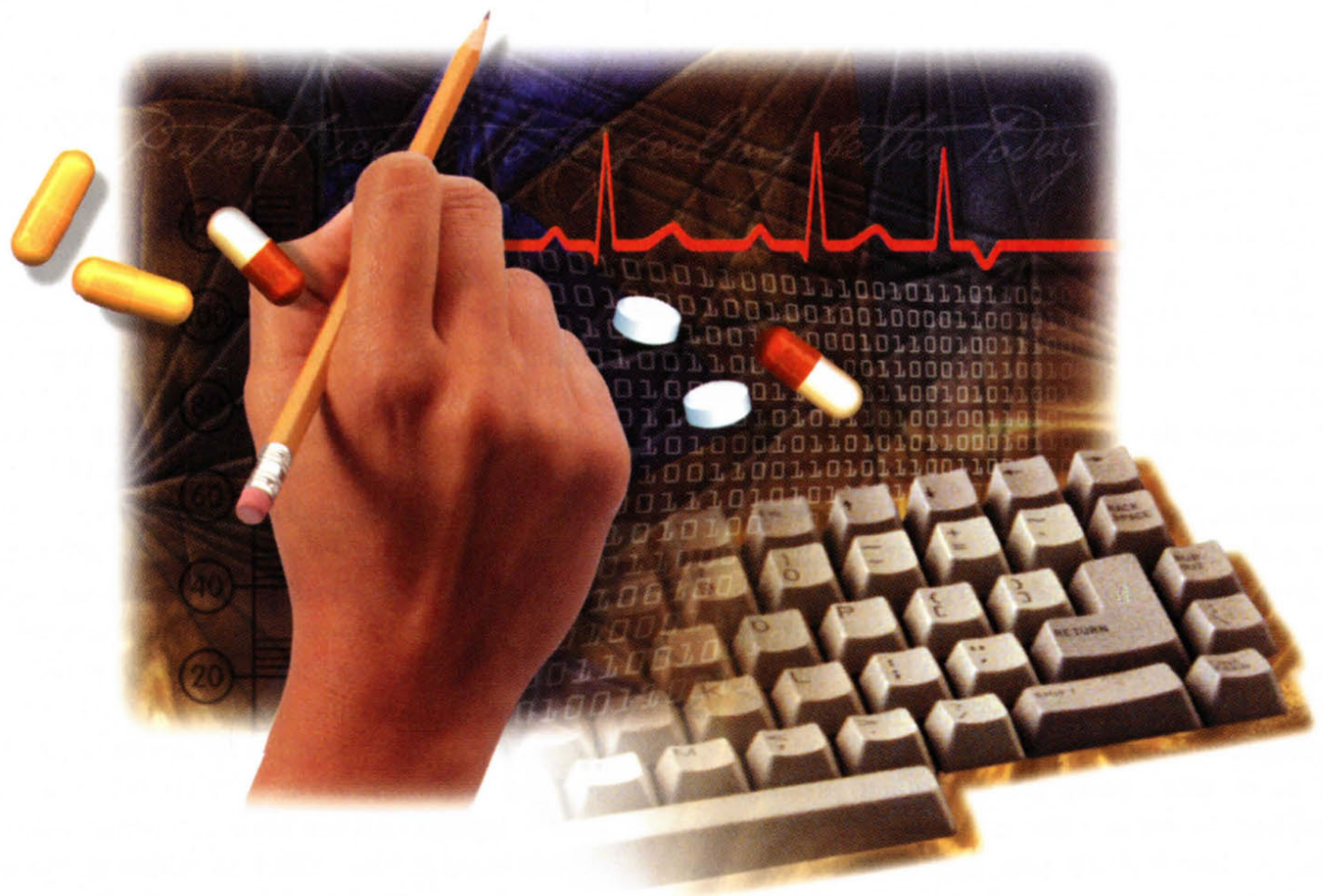

\section{Using information technology strategically in home care}

As home healthcare agencies examine new and innovative ways to deliver quality care more efficiently, the historical role of information technology as a way to automate clerical tasks will be significantly broadened to facilitate the true value of technology to home care providers. More importantly, a reduction in time spent on paperwork will allow agency caregivers to spend more time with clients. This article looks beyond the boundaries of desktop computing and examines the costs and benefits of network computing to develop strategic advantages for home healthcare agencies.
Too often, technology is used to automate production and thus reduce skill and labor requirements. But its potential to inform organizational members about the work process and thus improve operations and increase innovation is the aspect of technology that will be most important to long-term organizational success (Zuboff, 1985, p. 5).

The dawn of personal computing almost 20 years ago and the proliferation of "mobile computing technology" in the contemporary healthcare sector has altered documentation and communication drastically for client care delivery in the home. Unfortunately, technology has been viewed in most cases as only a tool to allow "faster" rather than "better" interaction with

JERRYY A. BENSON, Macc, CPA, JEFFREY E. MICHELMAN, PHD, CPA, CMA, AND DOREEN RADJENOVIC, PHD, RN 
clients in the home healthcare industry (Bailey \& Dickson, 1993). Although current research, such as the Bailey and Dickson study, does an excellent job of addressing the efficiency improvements to be obtained through the use of information technology, it fails to demonstrate the ability to improve the quality of care through the resulting efficiency gains and improved diagnostic capabilities.

A modern day maxim posits that business success cannot rest on past accomplishments. Customers, more and more, demand quality products and services delivered at competitive prices. To succeed, home healthcare agencies must be able to provide superior performance in key areas. Agencies that outperform their competition in quality and cost-effectiveness will benefit in a marketplace of limited consumer dollars. As more and more third-party payers place pressure on providers to reduce the cost of care, the importance of home care will continue to increase. Economic pressures placed on healthcare providers call for dramatic and innovative changes in the cost and quality of service.

In examining how home healthcare agencies can integrate technology and quality, this article will explore four primary issues. First, information technology is an important tool for developing a quality/cost strategy. Second, inefficient use of technology can lead to lost revenue. Third, technology must be deployed appropriately for it to be effective. Finally, it is important to focus on staff and management roles in any technological application. Projections about the future of information technology in home healthcare and cautions for system implementation are presented.

\section{Information Technology: A Quality/Cost Strategy}

One means of contributing to increasing quality service while simultaneously containing costs is to use information technology in the delivery and

Jerry A. Benson, Macc, CPA, is Adjunct Instructor of Accounting, College of Business Administration, University of North Florida, Jacksonville, Florida. Jeffrey E. Michelman, PhD, CPA, CMA, is Acting Associate Dean, College of Business Administration, University of North Florida, Jacksonville, Florida. Doreen Radjenovic, PhD, $R N$, is Assistant Professor of Nursing, College of Health, University of North Florida, Jacksonville, Florida. recording of healthcare services within and across organizations. Information technology, for the purposes of this discussion, involves the use of portable computers and network services to process home healthcare data. Not surprisingly, most of the use of technology in the healthcare industry to date has been limited to automated billing and other business and payment systems. Yet the value of information technology easily can contribute to more efficient and effective clinical care (Braunstein, 1993; Campbell, 1994). To accomplish this, technology must move to the front line where agency caregivers work with the client.

Information technology-when used appropriately-becomes a powerful tool for facilitating relationships in the healthcare delivery process (Kim \& Michelman, 1990) and improves the cost and quality of care (Sutliff, 1996). The key to improved processing is the creation of a centralized database that contains timely and accurate information (Michelman \& Kim, 1991). In addition, through the use of diagnostic technology in the home, such as electroencephalograms, personal computers can facilitate the two-way exchange of data (Campbell, 1994). This interaction can be enhanced through the use of video conferencing technology (Jerram, 1995), which will facilitate interaction among the nurse, client, physicians, and other clinicians in remote locations (Turetsky, 1995).

Because accuracy and timeliness are critical in the billing process, the advantages mentioned previously can have a positive impact on the turnaround time required to receive payment from payer sources. This in turn should improve agency profitability and cash flow. By eliminating some of the nurse's "shuffling of paper," with more time spent on delivering care, better quality of care and higher staff morale should occur (Schneider, 1995).

A diagram representing computing relationships between home care agency personnel and outside agencies is depicted in Figure 1. Multiple notebook computers for agency caregivers (nurses and others) provide access to patient information and resources from varied locations. This model is developed around the agency's file server (containing the agency's patient/staff databases and electronic gateways to outside constituents and resources such as the Internet) as the focal point. All communication within and outside the organization is funneled through this central hub. As a result, the timeliness, accuracy of, 


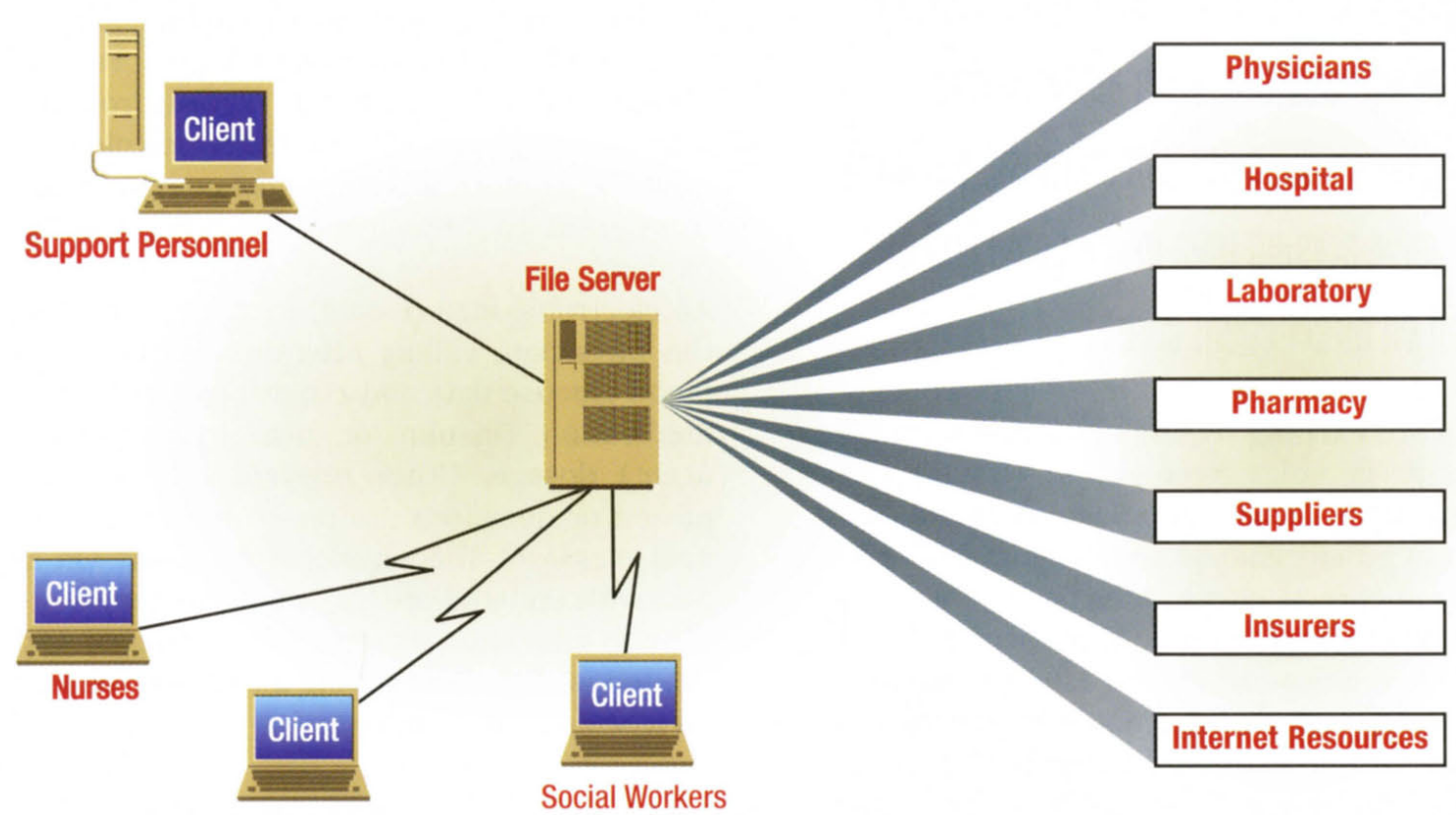

Home Healthcare Aides

Figure 1. A computerized information network for home healthcare.

and access to information for decision making and treatment are enhanced.

How can the use of portable computers in the overall handling of agency information add to quality and reduce costs? One way is through reducing the time agency caregivers spend on nonvalueadding paperwork in the field. A substantial portion of the expense of maintaining an effective home care agency is nursing salary requirements. Nursing efforts spent on activities that do not add to the value of client care are wasteful (Deming, 1986). Because home care is extremely labor-intensive, providers need to find ways that not only save staff time also but improve treatment. If ways can be found to minimize the nonvalue-added labor activities, such as excessive paperwork, productivity will increase, but more importantly, nursing time in the home can be focused on direct client care.

How can a well-devised information system help? Information technology provides some unique strengths readily adaptable to handling the type of workload in a home healthcare agency. Portable computers, in particular, provide innovative ways to cut staff time spent on paperwork in the field and home office. The portable microcomputer effectively becomes the "field office" for treatment, education, and order entry of business communication. In developing this field office mentality, agencies should pay particular attention to using the technology to facilitate business transactions and clinical practice.

Available software providing electronic forms for creating complete documentation from a onetime entry of information may well fill the need of providing a system for entering client visit data. This documentation can be completed by the agency caregiver while in the client's home. The computerized forms will further allow staff to avoid "reentering" information about the patient that is "permanent"(including patient characteristics such as name, address, and medical history). In addition, through the use of well-designed screens and the availability of scanning handwritten nursing notes, the likelihood of missing data will be reduced. Better quality data that are entered quickly will allow the staff member to spend more time being a clinician and less time being a clerk. In addition, the ready access to historical information in the patient record allows the nurse to make better clinical decisions.

Technological advances in portable computers have created new possibilities in the replacement of the numerous forms and portable files currently required in documenting home visits. One 
If ways can be found to minimize the nonvalue-

added labor activities, such as excessive

paperwork, productivity will increase, but more

importantly, nursing time in the home can be

\section{focused on direct client care.}

of the more exciting technologies that is gaining popularity is voice recognition (Davis, 1994; Richman, 1995). This technology alone will offer significant enhancements to efficiency and effectiveness of care as client notes become more detailed and easier to record. In particular, patient interviews then can be stored as either sound or text files. As these dictated notes increasingly become part of the computer-based patient record database (Andrew \& Dick, 1995a; 1995b), home healthcare nurses will find it easy to gain information from a client's history (Barrett \& Hochstein, 1993; Dick \& Steen, 1991).

Although the amount of savings generated in terms of time and accuracy will be unique to an organization's structure, one estimate suggested an immediate savings of almost 25\% merely through the deployment of personal computers (Bailey \& Dickson, 1993). The use of pen-based, graphical, and voice recognition technologies enhances efficiency and increases the likelihood of appropriate deployment of the technology. An added benefit of automation is that it not only reduces time in the generation of plans of treatment, care plans, and summaries, but it also serves as a means for an agency to improve its documentation. Better documentation can help to ensure a defense against Medicare or other third-party payer delays and denials of payment.

A clinical example of how information technology can be used in home care for a client with diabetes follows:

- A computer-based patient record is created on the initial nursing visit from assessment data. This document (accessible to all agency personnel) is the permanent working record and includes the patient's history and physical examination notes, the home and community assessment, business information, a problem list, a care plan, and a diabetes self-management education record.
- Current and past laboratory results are retrieved via network access to a database and are transferred to the computerized patient record.

- Self-monitored blood glucose records from the week since hospital discharge are downloaded from the patient's meter into the computer and transferred to the physician's office via fax modem.

- An electronic mail (E-mail) message is sent to the physician, calling attention to the faxed blood glucose data and requesting a review of medication (insulin or oral hypoglycemic agent) dosage. Other relevant data are reported or questions are posed in the same Email message. The physician responds via Email with updated orders or information.

- Written education materials are retrieved and printed for the client during a visit that focuses on teaching interventions.

\section{Inefficient Use of Technology Can Mean Lost Revenues}

One estimate is that overall documentation accounts for as much as $50 \%$ of home care nursing time (Braunstein, 1993). A vast amount of resources are being consumed in activities that attend to paper rather than to clients. For a nurse paid $\$ 30,000$ a year, this equates to spending the equivalent of $\$ 15,000$ on paperwork, which adds nothing to agency revenues. Add to this the nonvalue-adding time used in traveling from home to home, and it is evident that home care nurses need more efficient ways of dealing with their record-keeping and record-processing burden. In addition, movement of these records in the office for evaluation, correction, coding, copying, entry into the patient billing system, and filing quickly magnifies the paperwork costs. In addition, each time a client record is moved or reentered, the integrity of the data is threatened.

As shown in Figure 1, "electronic" paperwork can be downloaded directly into the main computer system at the office or transmitted through a modem over the phone from the nurse's home. This information is then accessible on screen throughout the main system network, and is instantly available at the desks of each of the involved support personnel. Here they can make corrections, additions, or manipulations to prepare a finished product for billing and patient record distribution. This would eliminate the at- 
tendant duplication of effort involved in a manual system in which one first gathers and records the data on paper and later enters these same data into the office computer system. It is the elimination of the rekeying of data that not only reduces costs but also enhances data integrity. More importantly, through the use of record locking (a database control that allows only one user to write to a record at a time), client records always contain the most up-to-date information.

The availability of technology does not mean that it will be used. Unfortunately, thousands of dollars are spent on systems that are never used to their fullest potential. Much of this data-handling capability already may exist within current agency computer systems; however, its use may be limited because of a failure in implementation. The cost and quality gains that might be hoped for will not be realized without a plan to implement all of the system's capabilities efficiently and effectively .

For organizations not effectively using their currently available technological resources, the purchase of additional technology may not provide any advantage unless there is a well-devised plan to ensure its implementation. This observation is not intended to discourage the move toward more technology. On the contrary, the future success of healthcare organizations depends on the successful integration of information technology (Kim \& Michelman, 1990). Rather, it is an admonition not to settle for the idea that the mere installation of technology somehow makes an organization more competitive.

\section{The Benefits of Using Technology Appropriately}

Another beneficial application of computer information technology that improves productivity and quality care is the use of software packages designed to improve scheduling. In a home care organization of any size, scheduling can consume enormous amounts of time. With multiple staff working in varied geographical areas, it is difficult to coordinate travel and patient visits to minimize driving time. Requests for specific staff members by patients, emergencies, staff illnesses, etc., can make planning quite difficult. Scheduling programs designed to provide staffing flexibility and geographical sensitivity can minimize the time spent matching staff members and client visits. Continuity of care can be enhanced by the avail- ability of detailed information concerning all clients when staffing switches are required because of vacation, in-service, termination, or promotion. Not only can using this scheduling system reduce managements' staffing needs, it also will provide a more efficient use of the present staff to make additional client visits each week. By staff members' connecting a portable computer to the centralized computer system via a modem, agency caregivers can readily access scheduling and patient information necessary for implementing the week's or day's assignments. In addition, as client needs change because of field observations, these data can be reflected in the scheduling program.

Information technology is often essential in maintaining competitiveness, but it may not be capable of achieving a competitive advantage where none existed before. In essence, technology will not fix a poorly devised business strategy or failure to use its full capabilities (Hammer \& Champy, 1993). However, it is important to understand that the development of a substantive information system is an integral requirement for maintaining competitiveness in today's healthcare environment (Kim \& Michelman, 1990). If inefficiency in daily operations is allowed to impose itself in an automated structure, the overall benefits to be derived from the technology may be far less than the expenditures incurred.

Little is known empirically about the impact of bringing a computer into the patients' home on client outcomes. Automation of a hospital unit has been shown to decrease time spent in documentation activities and increase time spent in direct care (Pabst, Scherubel, \& Minnick, 1996). Recently, home healthcare experts identified outcomes of care, cost of care, and use of portable computers as among the top 10 research priority questions in home healthcare (Albrecht, 1992). Vendors such as Home Care Information Systems Inc. now stress the importance and availability of outcome information as part of the agency information system. Relationships must be explored to understand how different types of technology are associated with various outcomes in home healthcare.

\section{Staff and Management Roles In Information Technology}

The addition of technology inevitably involves operational change, and one cannot predict how per- 
The future success of healthcare

organizations depends on the successful

integration of information technology.

sonnel will respond to change. It is always important to involve those who will be most impacted by a change in the process. Staff input always should be obtained before major expenditures in technology are made. Agencies should carefully evaluate not only the system to be implemented, but also the people who are going to use it. After all, the real value in any organization is created by people, not machines. Technology system development must be tailored to home healthcare requirements rather than agency needs adapted to existing systems (Campbell, 1994; Wilde, 1992).

Information system success will be linked directly to the quality and availability of training. Multimedia is one effective technique for staff training because it allows a natural transition to client education (Gleydura, Michelman, \& Wilson, 1996). Applications of multimedia include a combination of text, graphics, sound, still photography, and video. Although this type of presentation is often more costly to deliver, it makes staff training more informative and enjoyable. The development of multimedia presentations will allow staff members to make use of high-quality training materials in a self-paced field environment. The use of these training materials should help agency managers to take a hard look at the overall costs of staff training. A guideline for ensuring a smooth transition from a manual to an automated system is that an organization should expect to spend approximately the same amount of money on training each individual that it spends on each personal computer purchased (Chabrow, 1995). Although this might appear to be economically painful for the organization in the short run, the long-term benefits should be considered.

If technology in the form of improved information systems is to become a viable reality in enhancing the bottom line while ensuring quality service, it will require management's commitment to agency leadership in the introduction, implementation, and evaluation of new systems. Management must see itself as a participant in the process of meeting client and staff needs while providing direction for enhanced competitiveness in the area of technology.

Technological solutions in and of themselves will not reduce costs and raise quality. It is the people destined to use these tools who will make the difference. Management must see that technology's front-line users are first consulted, then trained, and consistently kept informed about system progress and changes. As the types of technology and their levels of complexity continue to increase, the only thing certain is that training must accompany change on an ongoing basis (Chabrow, 1995).

As management's plans for technology change, it often is faced with reminders of prior failures. As a result, the deployment of information technology should be planned to achieve a "payback" in 1-2 years, depending on the implementation schedule and cash flow requirements. In this way, problems can be addressed and solutions found in an amount of time that gives everyone room to customize the system to agency needs. To help management anticipate future needs and plan for a realistic program of implementation, the following guidelines should be used:

- Some staff members will be indignant toward the new technology; these staff members should be consulted early on and included in the system development process so that their misgivings can be addressed.

- Training users to use the technology will be significant in terms of time and expense.

- Telecommunications costs should be included for those areas in which long-distance communication costs apply.

- Although local and wide area networks increase the value of technology significantly, they also increase the need for technical support and present the potential for problems.

- Buying minimal hardware configurations should not be considered because vendors often underestimate processing requirements, and new software releases will make recently purchased basic systems obsolete.

- All hardware and software should be purchased with an upgrade path in mind.

- It is important not to rely on vendors who sell products and services based on promises; system development should be structured around tangible results rather than future plans or concepts.

- Agencies should be cautious in offering tech- 
nology-based services that are not reimbursable by third-party payers (Shu, Mirmina, \& Nystrom, 1996).

- Although costs are often possible to estimate and measure quantitatively, benefits are not. Consequently, instruments must be developed that measure costs and benefits qualitatively, and acceptable thresholds of results should clearly be established in advance.

\section{The Future of Computers in Home Healthcare}

Healthcare reform will continue to pressure providers to decrease costs while demanding increased quality. The key to making these changes a reality will continue to be information technology. Many of the changes that will occur already have begun (Pace \& Dittenbrenner, 1993). Yet the real value of information technology in the 21st century will be the ability of home healthcare agencies to involve clients more actively in the care process and improve client outcomes.

Information technology offers important potential for client diagnosis, treatment, and outcomes. Many applications are currently available, whereas others are still in development or are prohibitively costly. Yet, as technologies such as videoconferencing and on-line diagnostic information become affordable for staff members in the field, clients ultimately will benefit from these technological innovations. Although the future of information technology is certain, the speed of its deployment, as well as its costs and benefits, is less predictable. As home healthcare agencies attempt to apply information technology, the need to measure benefits beyond processing paperwork has never been greater. Healthcare providers who will be competitive in the year 2000 and beyond will be those who have implemented information technology advances with measured improvement in client care process and outcomes.

\section{REFERENCES}

Albrecht, M. (1992). Research priorities for home health care nursing. Nursing and Healthcare, 13(10), 538-541.

Andrew, W. F., \& Dick, R. S. (1995a). Applied information technology: A clinical perspective (Part 1). Computers in Nursing, 13(2), 80-84.

Andrew, W. F., \& Dick, R. S. (1995b). Applied information technology: A clinical perspective (Part 2). Computers in Nursing, 13(3), 118-122.
Bailey, J., \& Dickson, N. (1993). Analyzing home care information system needs. Caring, 34-37.

Barrett, J., \& Hochstein, B. (1993). Expanding the role of the medical record department. Journal of AHIMA, 64(9), 92-95.

Braunstein, M. L. (1993). The electronic patient records solution. Caring Magazine, 30-33.

Campbell, H. G. (1994). Applied computer technology for home healthcare professionals. Home Healthcare Nurse, 12(1), 56-58.

Chabrow, E. R. (1995). The training payoff. Informationweek, 535, 36-46.

Davis, M. W. (1994). Computerizing healthcare information. Chicago: Probus.

Deming, W. E. (1986). Out of crisis. Cambridge, MA: MIT Center for Advanced Engineering Study, 1986.

Dick, R. S., \& Steen, E. B., eds. (1991). The computerbased patient record. Washington, D.C.: National Academy Press.

Gleydura, A., Michelman, J. E., \& Wilson, C. N. (1995). Multimedia training in nursing education. Computers in Nursing, 13(4), 169-175.

Hammer, M., \& Champy, J. (1994). Reengineering the corporation. New York, Harper Collins.

Jerram, P. (1995). Videoconferencing gets in sync. New Media, 5(7), 48-55.

Kim, K. K., \& Michelman, J. E. (1990). An examination of the factors for the strategic use of information systems in the healthcare industry. Management Information Systems Quarterly, 14(2), 200-215.

Michelman, J. E., \& Kim, K. K. (1991). Multi inter-organizational information systems: Competitive strategies for teaching hospitals in the 1990s. Health Services Management Research, 4(1), 53-64.

Pabst, M. K., Scherubel, J. C., \& Minnick, A. F. (1996). The impact of computerized documentation on nurses' use of time. Computers in Nursing, 14, 25-30.

Pace, K., \& Dittenbrenner, H. (1993). A vision for health care: Electronic data interchange, Caring Magazine, 12(7),14-23.

Richman, D. (1995). Speech replaces point and click. Informationweek, 534, 44-47.

Schneider, S. (1995). Principles of productivity. Home Healthcare nurse, 13(3), 79-80.

Shu, E., Mirmina, Z., \& Nystrom, K. (1996). A telephone reassurance program for elderly home care clients after discharge. Home Healthcare Nurse, 14, 155-161.

Sutliff, D. P. (1996). Tips to improve communication. Home Healthcare Nurse, 14(3), 195-196.

Turetsky, K. (1995). Hospital rehabilitates from its paper overdose. Infoworld, 17(27), 49.

Wilde, D. J. (1992). Home health agency computer systems: Current status and future directions, Journal of AHIMA, 63(12), 82-85.

Zuboff, S. (1985). Automate/informate: The two faces of intelligent technology. Organizational Dynamics, 14, 5-18. 